\title{
Opening up the in-between: Ihde's Postphenomenology and Beyond
}

\author{
Gert Goeminne · Erik Paredis
}

Published online: 21 April 2011

(C) Springer Science+Business Media B.V. 2011

\section{Opening up the in-between: What's in it?}

"Opening up the in-between..." Another fancy title, one might think, another title that covers everything and nothing so that any paper fits this special issue's frame. Well, yes and no. In coming up with this title at the occasion of a one-day workshop in Ghent (Belgium) in January 2009 revolving around the work of Don Ihde, we explicitly had this double answer in mind. Yes, on the one hand we wanted to bring together a range of issues and themes as broad as possible. On the other hand, no, we did not welcome whatever contribution people might come up with as we are convinced that Ihde's philosophical stance, rather than focusing on a specific theme, embraces a particular way of revealing and interpreting the world. As overtly argued and illustrated throughout this issue, the relation between human beings and their world takes centre stage in Ihde's work: human beings and their world are viewed as mutually constituting each other or, in other words, human beings are what they are thanks to the ways in which they are situated in their world. It is this 'in-between' point of view that also takes centre stage in this special issue.

In his 1990 book "Technology and the Lifeworld: from garden to earth" Don Ihde nicely describes how a life in the mythical Garden of Eden without technology would be no human life at all and how—quite contrary-human existence has always already been permeated by things and artefacts, be it Adam and Eve's fig leave, Galileo's telescope or the ultrasound image of an unborn child. Indeed, strongly holding on to phenomenology's focus upon embodiment, and building on Heidegger's existential account of tool-use in "Being and Time", Ihde argues that the human-world co-constitution relation is almost always mediated by things, by technological artefacts. This eventually brings Ihde to his relational ontological trinity of 'human-technology-world', focusing on the non-neutral role of materiality in

G. Goeminne

Centre Leo Apostel, Vrije Universiteit Brussel, Krijgskundestraat 33, 1160 Brussels, Belgium

G. Goeminne $(\varangle) \cdot$ E. Paredis

Centre for Sustainable Development, Ghent University, Poel 16, 9000 Ghent, Belgium

e-mail: gert.goeminne@vub.ac.be 
a hermeneutic as well as an existential dimension: on the one hand, technologies help to shape how reality can be present for human beings, by mediating human perception and interpretation; on the other, technologies help to shape how humans are present in reality, by mediating human action and practices.

With the organization of the workshop and the publication of this special issue, we wanted participants to embrace and think from this in-between human-world stance. And yes, from this point of departure, that is to say from this perspective, one can look at a variety of themes and issues, as will be illustrated by the breadth of scope covered by the different contributions of this issue. So, the title "opening up the in-between" indeed allows one to plug in whatever issue one would like to plug in. But, on the other hand, this title does not cover whatever, because it does matter how one addresses the issue. It does matter from what stance one is talking; the way of revealing the issue at stake is of essence here. Thinking in terms of the mutual constitution of human and non-human clears the way to dwell on the 'in-between' of these human/non-human poles, rather than always already falling back to either of both sides, be it subject/object, social/technical or real/artificial. All of the papers presented here take up that challenge and, although different groupings were possible, we have chosen to present them in three clusters: a first cluster dealing with philosophical aspects of the subject-object divide such as embodiment, transparency and opacity; a second one gathering postphenomenologically refined reflections on our technologically conditioned society and finally a third cluster, inscribing itself in Ihde's 'empirial turn', gathering empirical investigations of human-technology-world relations.

\subsection{In-between the Objective and the Subjective: About (re-)Embodiment, Transparancy and Opacity}

Setting the stage, Don Ihde's own contribution "Stretching the in-between: embodiment and beyond" could stand as a paradigmatic example of his particular, distinctive style of doing philosophy. Drawing on personal experiences, Ihde describes how-over the years-he has been confronted with his own perceptual limits and this brings him to the question how it is possible after all to perceive such a thing as a perceptual limit. His answer: by means of technological, instrumental mediation such as provided by a Buddhist brass gong that keeps vibrating beyond Ihde's own audible experience. Further dwelling on this idea of recognizing human horizons through technological mediation, Ihde argues that there is a fundamental difference between the instruments of the first and the second scientific revolution. In the first case, embodied-perceiving humans discover particular aspects of perception beyond perception (microscope, telescope, ultrasound, infrared,...) within a wider whole body experience: so is infrared discovered as an 'extension' within the color spectrum by feeling heat. With the imaging technologies of the second revolution however (X-ray, gamma-wave telescopy, ...) the recognition is more closely tied to perceptions presented by the instrument. Here, Ihde argues, a 'critical hermeneutic' interpretation is needed to understand the phenomenon, that is to perceive the image gestalt and to interpret it in its beyond-experience context. In both the isomorphic and the non-isomorphic case, however, bodily-perceptual skills are involved that are acquired through training and the development of expertise. With the idea of 'the embodied human' as 'our anthropological constant', Ihde once again lays bare the core of his philosophy, inscribing itself in an inter-relational ontology: human-world changes are such that for every change in a 'world' there is a correspondent change in the 'human'. The specific contribution of his oeuvre, Ihde finally argues, is a sensitivity to materiality and its inclusion into the notion of intentionality itself. 
In her contribution, "Technology and the body: the (im)possibilities of re-embodiment", Helena De Preester goes in depth into the issue of embodiment, drawing extensively on philosophical as well as cognitive science sources. In her attempt to answer the age-old question to what extent we can 'technologize' our bodies, De Preester argues for a more rigorous distinction between body extensions and incorporation of non-bodily objects into the body, calling the latter 'real re-embodiment'. Discussing three categories of extensions/prosthesis, i.e. limb, perception and cognition, she suggests conditions of possibility for reembodiment that ask for radical alterations in the motor and/or sensory constitution of the human subject as well as in its subjective experience.

Yoni Van den Eede's paper "In between us: on the transparency and opacity of technological mediation" puts forward an attempt at a theory of technological mediation as such. Taking the differentiation between 'what we percieve' and 'what we don't percieve' when we use a technology as a heuristic instrument, Van Den Eede pins down a most important characteristic of technological mediation: its appearance as either 'there' (opaque) or 'not there' (transparent) — while it is still there. In putting forward a broad analysis of technological mediation in terms of 'transparency' and 'opacity' within several theoretical frameworks such as Ihde's postphenomenology, Latour's 'actor network theory' and Feenberg's 'critical theory of technology', he distills an essential contradiction between transparency of use and transparency of social origins and effects. In this sense, Van den Eede's paper also constitutes a nice bridge between papers of this first cluster, focusing on user aspects of technology, and those of the next cluster that deal with the societal context of science and technology.

\subsection{In-between the Technical and the Social: Thoughts and Afterthoughts on our Techno-Scientifically Conditioned Society}

What does an in-between perspective on humans and their world bring about in conceiving the relation between science and society? In an attempt to sketch the contours of an answer to this multi-facetted question in her paper "In-between science and politics", Karen François draws on the work of Bruno Latour who prefers to speak in terms of human and non-human actants weaving the world. Together with Latour, she traces the categorisation of science and politics back to Plato's allegory of the cave. Referring to Plato's representation of the social world and the world of truth as completely separated domains, she argues how such a dichotomous thinking makes us politically impotent vis-à-vis the typically hybrid humannon-human issues in our techno-scientifically textured societies. François further draws on the Latourian notions of 'matter of fact' and 'matter of concern' to make a plea for a 'politics of concern' in which both humans and non-humans are represented.

The next two papers, respectively by Goeminne and Paredis, take this discussion to a more concrete level in explicitly relating their contribution to the discourse on sustainable development, noting that the latter has taken so little notice of the later post-positivist developments in contemporary thought on science and technology. It is indeed striking that conceptions of technology as mediating human-world relations have hardly raised any attention, leaving sustainability discourse hopelessly torn apart between technophobia and technophilia.

In his article "Postphenomenology and the politics of sustainable technology", Gert Goeminne argues that this gap has been maintained from the philosophical side as well: whereas post-positivist thought has taken down the unworldly, representationalist account of science and technology and replaced it with a practice-inspired image of science and technology as culture, its political focus has been mainly restricted to an unravelling of 
the interwoven techno-scientific and socio-political aspects of scientific and technological practice. In elaborating on a relational normativity based on Rudolf Boehm's notion of topical truth, Goeminne tries to expand postphenomenology's political reach beyond Ihde's recognition of the non-neutral, ambivalent character of science and technology. Grounded in the 'foundationless foundation' of postphenomenology's relational ontology, he shows how the concept of topical truth opens up a rich field for normative inquiry ranging from the grindingly ordinary of our everyday practices to the presumable isolated micro-worlds of science and technology in the making.

Erik Paredis picks up on this, coming from his particular perspective of sustainability transition studies. In his paper "Sustainability transitions and the nature of technology", Paredis gives a comprehensive and critical overview of the different views on technology embraced by different approaches to sustainable development. He further draws attention to the lack of discussion about the nature of technology within the sustainability community, leaving the place mainly to an outdated instrumentalist position. However, Paredis sees a glimmer of hope in recent research that focuses on the notion of sustainability transitions, sketching the latter's sensitivity to constructivist approaches to socio-technical systems. While this has caused a leap forward in grasping how radical changes in socio-technical systems happen and how these insights may be useful in advancing societal transitions towards sustainability, Paredis argues that a more explicit engagement is urgently needed with the political dimension of sustainable technology, both from the side of sustainability transitions research as well as from the side of philosophy of technology.

In the last of this second cluster, Robert Scharff critically questions the enthusiastically embraced idea that a post-positivist perspective, be it postphenomenological or other, allows to overcome age-old dichotomies. In his article "Displacing epistemology: being in the midst of technoscientific practice", Scharff bluntly asks: How do we become postpositivist about science, or about anything else-once we realize that this issue must be considered and resolved from the standpoint of life, that is, while remaining in the midst of things? Scharff approaches this question by reanalysing the 'Erklaren-verstehen' debate along the figures of Dilthey, Husserl and Heidegger. He thereby takes as a starting point that the very existence of the debate itself is an issue, arguing that it cannot be solved epistemologically. Along these lines, Scharff suggests that the question about what philosophical orientation is adequate to think about what is real and what we should do about it should become an inherent part of the philosophical questioning itself. In other words, he says, before we plunge into postphenomenological explorations of what there is and how we know it, we must have some 'preparatory' reflection on the question of what it means to 'be' a thoroughly contextualized, historically determinate philosophical questioner ... of anything. Thinking that we can move beyond age-old subject-object dichotomies by merely 'chosing' to think post-positivistic about something, he finally warns, might well end up into a symptomatic affirmation of what we claim to surpass.

\subsection{In-between the Real and the Artificial: Empirical Explorations in art, Architecture and Media}

The last four contributions of this special issue illustrate the breadth of scope postphenomenology may aspire to cover by showing how the latter allows to understand art, architecture and media as forms of human-world assemblages in the sense of engaged, situated practices.

In his contribution "The screen as an in-between" Robrecht Vanderbeeken makes an attempt to develop a philosophical analysis of the impact of the rise of audiovisual media and 
popular Western television culture in creating a new mediated world, blurring the boundaries between what we perceive as 'real' and 'virtual'. Drawing on examples of so-called 'augmented reality' and 'mixed reality', he argues that the screen can be conceived as a virtual invader in our daily lives, manipulating the relation between onlooker and the world in a double manner: it mediates our perception of reality and it generates a new reality in a new mediated environment. In this sense, Vanderbeeken's take on the screen as an in-between could be seen as a concrete application of the transparency theory put forward in the paper by Yoni Van Den Eede. Juxtaposing Badiou's 'passion for the real' and Zizek's 'passion for the virtual', Vanderbeeken concludes that the laid-back enjoyment of escapism in a clean virtuality now seems to be counterbalanced by the excitement as well as the anxiety for the inescapable encounter with a fusion of the real and the virtual.

How new media affect our engagement with the world is a vital question, agrees Ike Kamphof in her paper "Webcams to save nature: online space as affective and ethical space". In the line of Ihde's postphenomenological view that the intentionality of things only manifests itself within a particular user context, Kamphof argues that media and users form assemblages of technologies and bodies in contexts of doing something. Therefore, she follows up on Ihde's plea to 'do phenomenology': her exploration of the workings of conservation websites and how these can be understood as providing caring spaces constitutes an empirical case study on the ethical and affective transparency of webcam-mediated engagement with the animal world. Considered as affective and ethical spaces, Kamphof concludes, conservation websites can only be understood when the intimate, dynamic and always practical relation of users and technology is recognized.

In their paper "Performing phenomenology: negotiating presence in intermedial theatre" Kurt Vanhoutte and Nele Wynants also pick up on Ihde's emphasis on the empirical nature of his philosophy as they argue how intermedial theatre could be seen as a way of staging postphenomenological research. In analyzing ' $W$ (Double U)', a performance by a multidisciplinary team of artists and researchers called 'CREW', they show how the use of immersive technologies in the context of a live stage, gives rise to a dialectics between an embodied and a disembodied perspective to the perceived world. Mounting an omni-directional camera on the heads of two 'immersants' and swapping the latter's visions, a rupture is installed between the embodied and the perceived world. In this way, W (Double U) can indeed be regarded as a truly postphenomenological experiment, which allows both the immersants as well as CREW's members to play around with technology and perception as well as reflection.

Finally, Soren Riis' paper "Dwelling in-between walls: the architectural surround" takes us on a tour of some of the most enigmatic buildings in the world arguing that Ihde's philosophy of technological mediation could be employed to construct a topology of architecture based on human experience. Riis' postphenomenological approach to architecture consists in showing how buildings can be understood as consubstantial human-technology wholes, which frame experience and thus help reveal different new worlds. To conclude his endeavour, Riis challenges all of us to experience one and the same built environment in a sequence of encounters based on Ihde's four different relations to technology. And so our thoughts wander off and we imagine taking the elevator to the top of the Eiffel tower early in the morning to look out over Paris as the city wakes up (embodiment relation) after which we descend and gaze at the tower from a distance and try to read its material language, revealing a sense of late nineteenth century French culture and its industrial momentum (hermeneutic relation). Around noon we buy some cheese and wine and have a pick-nick at Champ de Mars enjoying the tower's shadow (background relation) after which we feel energized to climb 
its 1665 steps, actively engaging with this microcosmos of steel (alterity relation). Who ever said that philosophy is just armchair theory?

\section{Science, Technology and Social Change: Concluding reflections on the Question of Perspective}

We want to conclude this introductory paper by presenting some personal reflections that grew out of our shared history in sustainability research and that have also guided us in setting up this special issue. Being scientific researchers ourselves, we are deeply concerned by an apparent lack of both intellectual space and a sense of necessity within academic research circles to deal with issues of human well-being and topical societal relevance. Here, the focus is on becoming competent in a particular field of research, competency being measured by the number of publications. In this context, fundamental issues of human existence are regarded as 'soft' questions as compared to the 'hard' research questions of science and it is our impression that 'soft' issues of human well-being only seem to become a theme for the scientist as a hasty afterthought late in the day, when the 'hard' work of science is done. Under the ideal of 'freedom of research', the non-interestedness in social relevance is even regarded as a necessary condition for good science, claiming that the benevolent societal impact is something that will eventually happen, as the necessary outcome of a supposedly unidirectional flow leading from science to society.

This disquieting observation is in our view mirrored by an analogue pattern of thought within policy circles. Intensive experience with policy preparatory research in sustainability issues has repeatedly shown us that whenever policy turns itself to science, this is almost always governed by a quest for a unequivocal framing of problems as well as for unequivocal solutions to these problems. All this is motivated by the same one-dimensional frame of thought that separates science from society and in which knowledge is disconnected from the initial problems, methods and questions through which the scientists were intentionally involved with their research objects. A parallel observation can be made with respect to the realm of technology.

Digging deeper into this, one eventually stumbles upon the age-old question of perspective through which humans, be it scientists, artists, designers or politicians, are involved with their world. It is also the same question of perspective that runs through all the contributions of this special issue. From a philosophical study of rubber hand illusions over a socio-political investigation of the role of technology in sustainability transitions to the live staging of intermedial theatre: all papers presented here take the question of perspective at heart. As mentioned in the introduction, this has been our very objective. Connected through a particular way of addressing an issue we have brought together here people -call them philosophers- that dig deep into the metaphysical and ontological foundations of our society as well as people -call them politicians- that think about transforming our society through media, art, architecture or sustainable development policy. We are really convinced of the creative potential present in the tension 'in-between' the philosopher, thinking about the world, and the 'politician', willing to act in the world, the 'in-between' tension being provided by the question of perspective. It is our hope that this special issue may spark further cross-disciplinary dialogue on science, technology and social change.

In this respect, we finally want to draw the reader's attention to the open-peer commentary approach adopted here. This special issue comprises two volumes, the first one containing the original papers we have briefly presented above, the second containing two peer-commentaries per paper followed by a final reply by the author. In this way, we have 
striven to open up the scientific debate beyond the contours of traditional peer review. Taking stock of the different commentaries and replies, the question of perspective is perhaps even more prominently present here as authors were challenged to rethink as well as rephrase their 'point of view'. This leaves us with the pleasure to thank all contributors for their constructive attitude as well as their patience in seeing this special issue come real. And real it is! 